\title{
The role of camel production on household resilience to droughts in pastoral and agro-pastoral households in Uganda
}

\author{
Robert Asiimwe ${ }^{1 *}$, John Herbert Ainembabazi ${ }^{1}$, Anthony Egeru ${ }^{2,3}$, Rosemary Isoto ${ }^{1}$, Daniel Knox Aleper ${ }^{4}$, \\ Justine Namaalwa ${ }^{2}$ and Gracious M. Diiro ${ }^{1}$
}

\begin{abstract}
Recurrent and prolonged droughts have exacerbated the problems of pasture and water scarcity in arid and semiarid lands (ASALs), hence, the need for immediate and long-term adaption strategies to such shocks. Camels are increasingly being integrated into mainstream livestock production systems as an adaptation strategy to droughts. However, rigorous empirical evidence remains scarce on the role of camel-rearing in household resilience to droughts. This study used cross-sectional data from 116 households in the Karamoja sub-region of Uganda to examine the effect of camel adoption on household resilience to drought. Resilience to drought was measured as an index constructed from consumption- and income-smoothing indicators using the principal component analysis (PCA) method. The effect of camel adoption on household resilience to droughts was estimated using Lewbel's estimator. Descriptive statistics show that camel tropical livestock units (TLUs) constituted 25\% of the total TLUs of the herd among adopting households. PCA analysis shows that income-smoothing factors (increased off-farm income and alternative sources of income) had the greatest contribution to resilience. Econometric results show that a unit increase in the proportion of camel TLUs significantly increased household resilience to droughts by 20\%. The study recommends increased emphasis on income diversification both on-farm and off-farm across programmes that aim to build pastoral household resilience to droughts.
\end{abstract}

Keywords: Resilience, Pastoralism, Karamoja, Camels, Droughts

\section{Introduction}

Pastoral and dry land livelihoods are negatively affected by climate variation-induced shocks (United Nations Development Program 2009) through recurrent and prolonged droughts which constrain access to water and pasture for livestock. This has led to serious ecological and economic consequences to rangelands and rangeland users, especially in Africa's dry lands (Vetter 2009). Recurrent droughts lead to increases in incidences of certain livestock diseases and livestock deaths; deterioration of livestock conditions at times force pastoralists to alter their herd structure; and a collapse of livestock

\footnotetext{
* Correspondence: robertasiimwe4@gmail.com

${ }^{1}$ School of Agricultural Sciences, Makerere University, Kampala, Uganda Full list of author information is available at the end of the article
}

markets (Opiyo et al. 2015). These reinforcing effects constrain pastoralists' income and family nutritional security in the affected areas.

It is expected that increasing variability in climates will continue affecting livestock production systems in all parts of the world, including the rural poor who have livestock as their main source of livelihood (Kima et al. 2015). Increase in evapotranspiration due to increased warming of the Earth may outpace increases in precipitation, thus increasing terrestrial aridity ${ }^{1}$ (Brookshire and Weaver 2015). These effects will alter landscapes, ecosystems, and conditions where people live. According

\footnotetext{
${ }^{1}$ Aridity describes the water deficiency of a given climate and is commonly characterized by the ratio of precipitation to potential evapotranspiration (Lickley and Solomon 2018).
} 
to Lickley and Solomon (2018), increased aridity contributes to more frequent droughts, severe soil moisture deficits, decreases in carbon uptake, and the expansion of global drylands. As the global climate continues changing, arid and semi-arid lands will increase by 5 to $8 \%$ in Africa across different climate scenarios, thereby resulting in exposure of between 75 and 250 million people to droughts by 2080 (Intercontinental Panel on Climate Change 2014). The increase in arid and semi-arid lands will in part drive the change in ecological systems and survival tactics of the affected communities, which are mainly pastoralist communities (IPCC 2014).

The hot and dry nature with low and erratic rainfall of arid and semi-arid lands (ASALs) leaves few livelihoods that are suited to this arid environment other than mobile livestock-keeping of mostly cattle, goats, and sheep which is particularly well adapted (Oxfam 2008). However, climate variability manifested in the form of recurring drought is making it increasingly hard for cattlethe most important livestock species in African dry lands to survive in the ASALs (Kagunyu and Wanjohi 2014). According to Kagunyu and Wanjohi (2014), the drought of 2005 to 2006 in Kenya reduced cattle, goat, and sheep herds by up to $70 \%$ in the heavily affected areas, which left the affected communities poor and hence more dependent on aid.

Communities in ASALs have shown resilience over time to such conditions as long droughts, and pasture and water stresses, through adoption of livestockdependent livelihoods that are well suited for such terrains. Traditionally, pastoral communities survive the effects of drought through breeding locally adapted livestock species and diversifying livestock species kept (like cattle, goats, sheep, camels, donkeys, and poultry), and through resource management practices like calf grazing paddocks which are becoming common in East Africa (The International Union for Conservation of Nature (IUCN) 2010). Pastoral tribes (Samburu and Turkana) in northern Kenya have begun to increase the number of camels that they manage, substituting them for cattle in order to have more drought-resilient livestock (Kagunyu and Wanjohi 2014, 2015; IUCN 2010). Kenya's camel population increased from 0.9 million in 1999 to three million in 2009 (Kagunyu and Wanjohi 2014) despite the increased occurrence of droughts within this period.

Zwaagstra et al. (2010), in their assessment of the impacts of the 2008-2009 droughts in northern Kenya, found out that communities that traditionally never adopted camels were increasingly integrating camels into their herds as, in part, an adaptation strategy to drought occurrence. This was due to high death rates of cattle and other livestock during the drought periods. Further, some communities did not prefer keeping cattle alone because of their inability to withstand many days without water during the drought periods. In the dry north, preference of integrating camels into mainly cattle production systems in dry lands by some communities that did not previously keep camels had been reported in earlier studies (Farm-Africa 2002).

Camels present a unique opportunity for adaptation to droughts and varying pasture quality in ASALs. They are able to survive well in ASALs due to their biological and physiological adaptations which help them to cope with harsh environmental conditions (Kagunyu and Wanjohi 2014; Yosef et al. 2014). They drink less water and are able to stay for many days without water due to their tolerance of dehydration compared to other livestock species. They are able to convert the scanty plant resources of the ASALs into milk, meat, and fibre (Ahmad et al. 2010). They almost have no competition for feed with other animals, as they are hardy animals and comparatively eat less food (Khan et al. 2003). Additionally, camels are kept as security against calamities and natural disasters like droughts and diseases that may be devastating to other livestock species kept (Mochabo et al. 2005), hence can be integrated into other production systems.

Camels are important livestock species in the subsistence economy of rural pastoral communities especially in ASALs (Aujla et al. 2013). They contribute to household food security by provision of meat and milk (Ahmad et al. 2010). They are used as pack animals for transport and provide household income through sale of live animals, meat, milk, and other by-products like hair and hides (Aujla et al. 2013; Faye et al. 2010; Mochabo et al. 2005). Field and Karuiki (2005) estimated that the volume of milk produced by camels is six times higher than that produced by indigenous cattle reared in the dry lands especially during the dry periods. Mochabo et al. (2005) further identified that camels are given as bride price among some groups in Kenya.

The contribution of camels to household subsistence and national economy in developing countries is generally obscured by inaccurate estimates of camel populations due to the lack of regular censuses and the fact that camel products seldom enter a formal marketing system (Ahmad et al. 2010). As such, the economic contribution of camel-rearing is often underestimated. Despite having unclear statistics, camel production is increasingly receiving much attention as a major source of food (meat and milk) in semi-arid and arid areas (Aujla et al. 2013). In some pastoral households, camel milk is an integral part of the food basket and household income and has a huge potential for poverty reduction (Musinga et al. 2008; Elhadi et al. 2015; Aujla et al. 2013). A number of existing studies, however, highlight milk as the main product, leaving out other camel products such 
as meat and blood that could also contribute to household income.

Extensive keeping of livestock is the major economic activity in the Karamoja region of Uganda due to its semi-arid nature. Though well adapted for such a climate, mobility of livestock in the region has been limited by chronic insecurity of the area in the past, as well as low-quality forage; limited access to water, especially in the dry season; high incidence of contagious livestock diseases, and limited access to veterinary services and livestock markets (USAID 2005; FAO 2018). These factors have limited the livestock-based development initiatives in the region, and as such the region still registers the lowest human development indices in the country (FAO 2018). While the Karamoja region holds 97\% of the camel population in the country (Uganda Bureau of Statistics 2010), little is known about the community's motivation for adopting camels, camels' impact on income-generation, and the role they play in the enhancement of resilience ${ }^{2}$ to droughts in regions so prone to recurrent and prolonged droughts. Incorporating camels into mainstream livestock production presents an opportunity for improved food security and income. Since there is little empirical evidence on the effects of camel adoption, this study therefore sought to establish the effect of camels on household income and pastoralists' resilience to droughts in the Karamoja sub-region.

\section{Study area}

The study was conducted in the districts of Moroto and Amudat in north-eastern Uganda (Karamoja sub-region) which lies between latitudes $1^{\circ} 30^{\prime}$ and $4^{\circ} \mathrm{N}$ and longitudes $33^{\circ} 30^{\prime}$ and $35^{\circ} \mathrm{E}$. These are semi-arid lands characterized by unpredictable rainfall and high temperatures (Egeru et al. 2014; Mubiru 2010). These areas border north-western Kenya, south-eastern Sudan, and south-western Ethiopia. The regions have three types of livelihood options; namely crop production, agropastoral and pastoralism, each of which are dictated by the amount of rainfall received in an area. Most of these areas have erratic rainfall or extended dry conditions, diseases and pests, low infrastructure, cattle thefts, bush fires, periodic low water, and limited pasture availability (FAO 2018). Karamoja is mostly semi-arid savanna covered with seasonal grasses, thorny plants, and occasional small trees (Mubiru 2010). The area is dominated by indigenous tropical grasses and mostly composed of Acacia species (Egeru et al. 2014). It is the poorest region in Uganda with over $80 \%$ of its people living below the

\footnotetext{
${ }^{2}$ Resilience can be defined as the ability of, and mechanisms used by, individuals and communities to cope with external shocks; the ability of those communities to self-organize after experiencing a shock; and the ability to adapt to such shocks mainly through social learning (Osbahr et al. 2010).
}

poverty line (Browne and Glaeser 2010; FAO 2018). In addition to cross-border conflicts, the region is also prone to increasingly frequent and severe natural disasters, especially droughts, in part as a result of climate change (Caffrey et al. 2013; United Nations Development Program (UNDP) 2009; World Food Program of the United Nations (WFP) 2009).

\section{Methods}

Data used in this study consists of detailed household information obtained from a cross-sectional survey conducted in January to February 2016. Semi-structured questionnaires were administered through local interpreters to a total of 52 camel herding households and 64 non-camel herding households. Key informant interviews were later conducted, guided by a key informant interview guide to validate the information from the household interviews. Two districts (Moroto and Amudat) were purposively selected due to the existence of high camel numbers, and key informant interviews guided the selection of the sub-counties; Rupa in Moroto and Amudat TC, Amudat, and Looro in Amudat District.

A snowball approach was used to identify the camel herding households, and the study respondents were selected depending on their availability and willingness to participate in the study. Information on household demographic characteristics, economic activities, and physical, social, and economic connectivity of the households was collected. Further, information on numbers of camels kept, camel products obtained, proportions of products consumed and sold, sale prices, other income sources, amount, and available resources such as land and other livestock species was also collected. Target respondents were household head, spouse, or older children familiar with household routine activities and camel-related activities.

\section{Data analysis}

The study examined the effect of smallholder pastoralist camel production in Karamoja on household resilience to droughts, using the conventional random utility model. In this framework, individuals were assumed to make rational decisions by choosing to rear camels if doing so maximized their expected utilities. Following Hanemann (1984) and Baltas and Doyle (2001), a random utility function for a smallholder farmer in Karamoja facing a decision to rear camels was specified as in Eq. (1) below:

$$
V i j=\bar{V} i j+\varepsilon i j=X i j \theta+\varepsilon i j, i=1, \ldots, n
$$

where $V i j$, utility of alternative $j$ for consumer $i$, is a function of the deterministic component $V i j$ and the 
random component $\varepsilon i j$; $\mathrm{X}$ is a vector of observed socioeconomic and demographic characteristics of the individual; and $\varepsilon$ is the stochastic component of the utility function representing the unobserved attributes affecting individual's choice of the practice, heterogeneity in tastes, and measurement errors.

A rational pastoral household would choose to adopt camel rearing if the expected utility derived from camels $\left(V i_{1}\right)$ was higher than that generated without camels ( $V i 0)$, given the constraints, such as access to resources, and information and knowledge about camels. Camel adoption and its role in enhancing household resilience to droughts was the focus of the study.

Camel adoption was expected to contribute to household food security through increased meat and milk availability (Ahmad et al. 2010) and additional household income through sale of live animals, meat, milk, hair, and hides (Aujla et al. 2013; Faye et al. 2010; Mochabo et al. 2005). Camel-adopting households obtain a higher social status and benefit by having constant milk supply despite variations in pasture and water availability. Being browsers, camels can thrive on the available scant vegetation and thus reduce the need for transhumance compared to the case of cattle. From the benefits of food security, increased income flows, and settlement, an adopting household was expected to be more resilient to the devastating effects of recurrent and prolonged droughts. Based on this background, a Drought Resilience Index was constructed for adopting and nonadopting households.

\section{Empirical methods}

\section{Construction of the household Drought Resilience Index}

Individuals, households, or communities faced with climatic or other risks will tend to prioritize between elements of the production, consumption, and ecological systems in which they are at the moment (Osbahr et al. 2010). Drought affects a household through its effect on crop and livestock production. For a subsistence household, this implies a direct effect on production and an indirect effect on consumption and/or expenditure behaviours. Due to the moisture stress-farm output and farm output consumption relationships, the effects of droughts can be assessed through observing changes in consumption or expenditure of a given household during drought relative to normal times. Measures such as consumption or expenditure-smoothing behaviours of individuals or households have thus been used to estimate the effect of droughts on households (Banda 2015; Giuseppe et al. 2016; Keil et al. 2008).

Direct and indirect methods of measuring resilience have been developed, with each having its own inherent analysis challenges. Several recent studies have used the direct approach to resilience measurement (Alinovi et al.
2008; Ciani and Romano 2013; Giuseppe et al. 2016; Guyu and Muluneh 2018; Osbahr et al. 2010). The direct approach is based on the construction of a Resilience Capacity Index (RCI) or resilience capacity matrix (RCM). The approach considers several household livelihood indicators such as alternative sources of income, access to productive assets, availability of and access to basic services (healthcare, education and extension), and social safety nets to determine household response to shocks (Ciani and Romano 2013). However, in a review of RCI indicators by Giuseppe et al. (2016) , the RCI now considers access to basic services (ABS), assets (AST), social safety nets (SSN), sensitivity (S), and adaptive capacity (AD) of an individual household as the fundamental pillars of resilience (Giuseppe et al. 2016). The mechanism of response in turn depicts the level of resilience of such a household at any given point in time. The empirical challenge with this method is that the variables used to determine the individual components in such an index if included in a regression model would introduce potential endogeneity. Therefore, the index from the direct methods cannot be used in an inferential work (Giuseppe et al. 2016) unless large data sets and a good number of relevant variables are available (Ciani and Romano 2013; Guyu and Muluneh 2018).

The indirect measure of household resilience was adopted in the determination of household Drought Resilience Index. This method has been used in recent drought resilience (Banda 2015; Keil et al. 2008) and food security (Giuseppe et al. 2016) empirical work to construct a Resilience Capacity Index that is used as a dependent variable in the inferential analysis. It used a set of determinants of resilience (including policyrelevant decision variables) to infer a given level of resilience to droughts. Construction of this index using the direct methods of resilience measuring would introduce potential endogeneity problems since some of the variables used in the construction of the index would be used as independent variables in the regression (Giuseppe et al. 2016). To avoid the endogeneity problem that would bias the estimates and thus the inferences drawn thereafter, indirect methods were more appropriate for this study.

Arising from multiple manifestations of drought effects, one variable alone may not have adequately represented the effect of a drought; thus, several variables were used to observe these effects. This necessitated the use of data reduction methods to adequately represent multiple variables without loss of information and then proceeding to use them in regression analysis. The principal component analysis (PCA) approach was adopted for this study due to its ability to summarize individual indicators while preserving the maximum possible proportion of the total variation in the original variables 
(Nardo et al. 2008). The study computed a Drought Resilience Index (DRI) for each household using the PCA approach.

Determinants of household resilience to droughts drawn from the literature (Banda 2015; Keil et al. 2008) were used to construct a Drought Resilience Index (DRI). Specifically, the variables chosen for the DRI included proportion of food consumed (Fc) in droughts as compared to normal season, months of food scarcity (Ms), and meals per day (Md) in times of scarcity as measures of consumption-smoothing capacity, and number of alternative sources of income (Ai) and proportion of total income that is off-farm (Ip) as measures of income stability in the event of droughts. As specified in Eq. (2), DRI was expressed as:

$$
D R I=w_{c} F c+w_{s} M s+w_{d} M d+w_{i} A i+w_{p} I p
$$

where $w_{n}$ was the proportions explained by the given factor in the PCA analysis used as weights; $n=c, s, d, i$, $p$, and the other variables are as described above.

\section{Estimating the effect of camel adoption on household resilience to droughts}

The study estimated the effect of camel adoption on household resilience to droughts. However, the decision to adopt camels and household resilience to droughts are potentially endogenous. Camel-rearing households may be systematically different from non-rearing households with respect to observed and unobserved attributes, resulting in inconsistent estimates of the effect of camel rearing on household resilience to the effect of recurrent and prolonged droughts. For example, most motivated pastoralists with higher management abilities and skills are more likely to adopt new resilience-enhancing technologies such as camel rearing. If so, the effect of adoption would be biassed upwards due to positive correlation with unobservable motivation to adopt resilience-enhancing technologies. Estimation of the effect using ordinary least squares estimation would thus yield biassed results. The natural candidate for circumventing this problem would be the use of external instrumental variables for the adoption of camels. There were difficulties in finding valid instrumental variables for the study. A method, which utilizes a heteroscedastic covariance restriction to construct an internal instrumental variable (IV), was used to allow parameter estimation (Lewbel 2012). Mishra and Smyth (2015) and Ventura (2018) have recently applied this method to facilitate the identification and estimation of parameters in the absence of externally generated instrumental variables. Using Eqs. (3) and (4) below, the Lewbel approach is adopted to the study as follows:

$$
\begin{aligned}
& Y_{1}=X^{\prime} \beta_{1}+Y_{2} \gamma_{1}+\varepsilon_{1} \varepsilon_{1}=\alpha_{1} U+V_{1} \\
& Y_{2}=X \beta_{2}+\varepsilon_{2} \varepsilon_{2}=\alpha_{2} U+V_{2}
\end{aligned}
$$

where $Y_{1}$ is the resilience to droughts and $Y_{2}$ is the camel adoption. $U$ denotes the individual's unobserved motivation which could affect their decision to rear camels and the ability to cope with shocks; $V_{1}$ and $V_{2}$ are random errors. It is observed that some of the parameters in the models cannot be identified without additional information. By either imposing equality constraints on the coefficients of $X$ (that is using ordinary least squares (OLS) regression), or assuming that one or more elements of $\beta_{1}$ are equal to zero, one could identify the parameters which would permit the estimation of the $Y_{1}$ equation using instrumental variables according to Lewbel.

However, if one assumes $Z$ to be a vector of observed exogenous variables ( $Z$ could be a subset of $X$ or equal to $X$ ), Lewbel argues that if Eq. (5) moment conditions are met, then:

$$
E\left(X \varepsilon_{1}\right)=0, E\left(X \varepsilon_{2}\right)=0, \operatorname{Cov}\left(Z, \varepsilon_{1} \varepsilon_{2}\right)=0
$$

and there is some heteroscedasticity of $\varepsilon j$, one can estimate the above set of equations by using $[Z-E(Z)] \varepsilon_{2}$ as an instrument, employing either two-stage least squares (TSLS) or generalized methods of moments (GMM). TSLS may be inefficient when heteroscedasticity is present in the regression errors, which is a precondition for implementing the Lewbel approach (Mishra and Smyth 2015); hence, GMM method in Stata was used to fit the model. Lewbel's own empirical work and Ventura (2018) have shown that the resulting IV estimates are very close to those using conventional valid IVs.

\section{Results and discussion}

\section{Socio-economic and demographic characteristics of the surveyed households}

This subsection presents selected socio-economic and demographic attributes of the farmer households included in the survey. The attributes presented in Table 1 include main livelihood activities of the household, human capital (household size and dependence ratio, household education completion, and age of the household head), access to cropping land and area of land cultivated, and financial capital (including per capita income, alternative sources of income, on and off-farm income, remittances, and access to credit).

The summary statics in Table 1 show that the two farmer categories are generally comparable with respect to most of the attributes except per capita income, income from the farm and non-farm sectors, and age of the farmer. Camel adopters were older and reported higher per capita income and income from the farm 
Table 1 Socio-economic and demographic characteristics of the surveyed households

\begin{tabular}{|c|c|c|c|c|c|c|c|}
\hline \multirow[t]{2}{*}{ Variable } & \multicolumn{2}{|c|}{$\begin{array}{l}\text { All households } \\
(n=116)\end{array}$} & \multicolumn{2}{|c|}{$\begin{array}{l}\text { Camel households } \\
(n=52)\end{array}$} & \multicolumn{2}{|c|}{$\begin{array}{l}\text { Non-camel households } \\
(n=64)\end{array}$} & \multirow[t]{2}{*}{ t-statistic } \\
\hline & Mean & Std. Dev. & Mean & Std. Dev. & Mean & Std. Dev. & \\
\hline Per capita income (UShs '000) & 163.06 & 303.767 & 231.67 & 419.315 & 107.32 & 138.063 & $-2.230^{* *}$ \\
\hline Occupation of household head (1, pastoralist; 0 , otherwise) & 0.74 & 0.440 & 0.75 & 0.437 & 0.73 & 0.445 & -0.190 \\
\hline Age of household head (years) & 49.62 & 14.975 & 54.19 & 13.776 & 45.91 & 14.982 & $-3.070^{*}$ \\
\hline Years of experience in rearing camels & & & 26.05 & 20.281 & & & \\
\hline Marital status (1, married polygamous; 0 , otherwise) & 0.74 & 0.439 & 0.81 & 0.398 & 0.69 & 0.467 & -1.446 \\
\hline Household size (continuous) & 11.05 & 5.138 & 11.27 & 5.010 & 10.88 & 5.272 & -0.410 \\
\hline Household member completed primary & 0.17 & 0.379 & 0.19 & 0.398 & 0.16 & 0.366 & -0.507 \\
\hline Dependence ratio & 0.67 & 0.818 & 0.71 & 0.823 & 0.64 & 0.819 & -0.423 \\
\hline On-farm income (UShs '000) & 1085.00 & 1471.227 & 1628.80 & 1728.317 & 643.16 & 1044.305 & $-3.791^{*}$ \\
\hline Off-farm income (UShs '000) & 411.35 & 1172.925 & 318.04 & 526.811 & 487.17 & 1507.846 & 0.771 \\
\hline Proportion of off-farm income to total income & 0.36 & 0.379 & 0.26 & 0.353 & 0.44 & 0.381 & $2.667^{*}$ \\
\hline Access to credit ( 1 , yes; 0 , otherwise) & 0.29 & 0.457 & 0.25 & 0.440 & 0.32 & 0.471 & 0.783 \\
\hline Number of alternative sources of income (continuous) & 1.00 & 0.780 & 0.92 & 0.788 & 1.06 & 0.774 & 0.9567 \\
\hline Assets owned ( $0=$ only agric; $1=$ agric and non-agric $)$ & 0.66 & 0.510 & 0.73 & 0.490 & 0.61 & 0.523 & -1.279 \\
\hline Crop area cultivated & 4.40 & 3.691 & 4.86 & 4.037 & 4.02 & 3.371 & -1.220 \\
\hline Feeling of food scarcity ( $1=$ yes; $0=$ no) & 0.93 & 0.254 & 0.88 & 0.323 & 0.97 & 0.175 & $1.788^{* * *}$ \\
\hline Months of scarcity & 5.49 & 4.622 & 5.00 & 4.847 & 5.89 & 4.622 & 1.010 \\
\hline Meals consumed per day in times of scarcity & 1.45 & 0.450 & 1.47 & 0.504 & 1.43 & 0.450 & -0.336 \\
\hline Proportion of food consumed in scarcity & 0.59 & 0.595 & 0.66 & 0.726 & 0.54 & 0.471 & -1.063 \\
\hline Received extension & 0.41 & 0.495 & 0.48 & 0.505 & 0.36 & 0.484 & -1.319 \\
\hline Member of social group & 0.41 & 0.494 & 0.31 & 0.466 & 0.49 & 0.504 & 0.291 \\
\hline Received remittances & 0.21 & 0.407 & 0.15 & 0.364 & 0.25 & 0.436 & 1.269 \\
\hline Distance to nearest input stockiest & 8.31 & 6.756 & 9.19 & 6.473 & 7.63 & 6.942 & -1.204 \\
\hline Distance to nearest extension office & 6.69 & 5.817 & 6.41 & 5.648 & 6.91 & 5.980 & 0.446 \\
\hline Distance to nearest health centre & 4.08 & 3.520 & 4.17 & 3.555 & 4.01 & 3.520 & -0.242 \\
\hline Distance to nearest primary school & 2.67 & 3.110 & 3.04 & 4.258 & 2.36 & 1.604 & -1.154 \\
\hline Distance to nearest secondary schools & 11.09 & 6.663 & 11.44 & 7.124 & 10.83 & 6.355 & -0.469 \\
\hline
\end{tabular}

***Significant at $10 \%,{ }^{* *}$ significant at $5 \%,{ }^{*}$ significant at $1 \%$

sector than farmers without camels. Higher per capita income may be an indicator of household resilience where households with low per capita incomes may have low savings and limited capacity to smooth consumption in the event of shock. Furthermore, the head of a camelrearing household was about 8 years older (54) than their non-camel counterparts (46). Age of the household head is likely to be associated with wealth accumulation in households and may lead to increased resilience to shocks in households.

Whereas there is no significant difference in off-farm income between the two farmer categories, nonadopting households registered higher non-farm income of UShs 487,170 (about USD 1145) relative to UShs 318, 040 (about USD 95) for the camel adopters (Table 1). It can also be noted that the share of non-farm income is significantly higher among the non-adopters relative to the adopters. These results suggest that non-camel farmers appear to compensate for the low farm income by engaging in the non-farm sector to smooth consumption.

Similarly, there is no difference in the level of education between the two household categories; completion of education is still very low, with less than $20 \%$ of the households reporting to have at least a member who has completed primary school (Table 1). Low education level affects the potential of household members to involve in alternative sources of income such as employment in the formal sector or participation in non-farm sectors. Education attainment affects the adoption of resilience- and income-enhancing technologies introduced in the community due to limited ability to synthesize new information and make an informed decision. Low education 
level could therefore lead to generally lower resilience in the community due to low adoption of resilienceenhancing technologies introduced.

The results in Table 1 further show that more camel-rearing households felt food scarcity than the non-camel-rearing households. However, both farmer categories of households reported a comparable number of meals eaten per day (1.45) and adjusted quantities of food in the periods of scarcity and plenty. Non-camel-rearing households reduced their consumption by almost a half (46\%) whereas camel household reduced consumption by $34 \%$ on average during times of scarcity. This means that camelrearing households were slightly less affected by food scarcity as measured through the reduction in food consumption during the times of scarcity-mostly due to droughts.

The average numbers of years of rearing camels in the adopting households were 26 years. However, differences were observed between the two districts, with significantly higher years of rearing in Moroto (38 years) than in Amudat (13 years). This shows that the rearing of camels is a relatively new practice in Amudat compared to Moroto.

\section{The level of household resilience to drought in Karamoja sub-region}

This study constructed an index of resilience to drought for each household using PCA, which helps to aggregate several variables measuring one latent variable into a single index. Following Giuseppe et al. (2016) and Nardo et al. (2008), a correlation analysis was performed to determine the existence of a strong association among the variables used in the analysis. The results of the correlation analysis are presented in Table 2. The results show a strong and positive correlation between alternative sources of income and proportion of off-farm income to total income. A strong negative correlation is noted between months of scarcity and the proportion of food consumed. The negative correlation is expected; increasing months of scarcity decreases the opportunities of a household to smoothen consumption for example from saved food. Thus, as the number of months households experience a drought increase, the households are more likely to respond to food shortages by reducing the proportions consumed of whatever food is available. Opiyo et al. (2014) and Muricho et al. (2019) stress the importance of income diversification in enhancing household resilience to droughts; this study used alternative sources of income and proportion of off-farm income to total income to capture the consumption-smoothing opportunities in the event of a drought and, hence, income stability indicators. Most households in rural areas produce most of their food and are more likely to resort to consumption adjustments in the event of droughts. Months of scarcity, meals consumed per day in scarcity, and the proportion of food consumed in scarcity as compared to normal times were used to account for the consumption adjustments of a household in the event of droughts and, thus, consumption stability indicators. The existing strong correlations justify the use of PCA as a dimension reduction method on the data. Bartlett's test of sphericity and the Kaiser-Meyer-Olkin (KMO) measure of sampling adequacy were also done to confirm the use of PCA.

The chi-square value for Bartlett's test of sphericity was 107.040 and significant at $1 \%$ level of significance, leading to the rejection of the null hypothesis and conclusion that the variables used in the study were inter-correlated and that the correlations did not result from a sampling error. This means that there were suitable correlations to warrant the application of PCA on the data.

The Kaiser-Meyer-Olkin measure of sampling adequacy yields a value of 0.503 , indicating a fair correlation between the included variables and an adequate sample to carry on with PCA. The result from these two tests shows confidence in the application of PCA as a method of dimension reduction of the data. The results from the principal component analysis are presented in Table 3.

Table 2 Correlation matrix for the variables used in construction of the index

\begin{tabular}{|c|c|c|c|c|c|}
\hline Variable & $\begin{array}{l}\text { Alternative sources } \\
\text { of income }\end{array}$ & $\begin{array}{l}\text { Proportion of } \\
\text { off-farm income }\end{array}$ & $\begin{array}{l}\text { Meals consumed/day } \\
\text { in scarcity }\end{array}$ & $\begin{array}{l}\text { Proportion of food } \\
\text { consumed in scarcity }\end{array}$ & $\begin{array}{l}\text { Months of food scarcity } \\
\text { in the last drought }\end{array}$ \\
\hline Alternative sources of income & 1.0000 & & & & \\
\hline Proportion of off-farm income & $0.448^{*}$ & 1.0000 & & & \\
\hline Meals consumed per day in scarcity & $-0.258^{*}$ & -0.147 & 1.000 & & \\
\hline $\begin{array}{l}\text { Proportion of food consumed in } \\
\text { scarcity }\end{array}$ & $-0.206^{* *}$ & -0.045 & $0.497^{*}$ & 1.000 & \\
\hline $\begin{array}{l}\text { Months of food scarcity in the last } \\
\text { drought }\end{array}$ & 0.052 & 0.118 & $-0.670^{*}$ & $-0.205^{*}$ & 1.000 \\
\hline
\end{tabular}

**5\% and ${ }^{*} 1 \%$ level of significance 
Table 3 Eigenvalues of the components

\begin{tabular}{lllll}
\hline Component & Eigenvalue & Difference & Proportion & Cumulative \\
\hline Component 1 & 1.964 & 0.674 & 0.393 & 0.393 \\
Component 2 & 1.290 & 0.406 & 0.258 & 0.651 \\
Component 3 & 0.885 & 0.301 & 0.177 & 0.829 \\
Component 4 & 0.584 & 0.307 & 0.117 & 0.945 \\
Component 5 & 0.277 & 0.055 & & 1.000 \\
\hline
\end{tabular}

Two components ( 1 and 2) in Table 3 had eigenvalues above 1 thus adequately capture the variation within a set of constructs (Nardo et al. 2008). However, component 1 yielded negative signs on the factor loading of the proportion of farm income and the number of meals consumed which contradict the expected signs. Component 2 on the other hand presented all signs of factor loadings for the selected variables as expected from the resilience literature and theory. Therefore, it can be concluded that the second principal component adequately captured drought resilience. The factor loading, expected signs, and summary statistics of the variables used in the construction of the resilience index are presented in Table 4.

The results show that number of alternative sources of income, and proportion of off-farm income to total household income are the highest factor loadings. This implies that income-smoothing opportunities had a higher bearing on resilience consistent with the findings of Opiyo et al. 2014 who found that complementary source of income as well as access to off-farm income was positively related with reducing household vulnerability to climate-induced stress-thus increasing resilience among pastoral communities in Kenya. Opiyo et al. (2014) and Keil et al. (2008) further show that the risk of exposure to droughts is almost uniform within stated geographical confines. Thus, the livelihoods dependent on natural resources are likely to be uniformly affected. This implies that household resilience is more likely to be shaped by factors the households ability to diversify its income beyond the most affected farm sectors or beyond the farm as a whole. Muricho et al. 2019 assert that participation in the markets and food aid then become the next available options when the households fail to meet their food needs from their own production. This is supported by the relatively lower factor loading for consumption-smoothing options because droughts limit households' consumption from own production. Using the component loading as the weights for the variables used in the construction of the DRI, equation 2 earlier presented was modified to produce equation 6 below. Equation 6 was used to construct the drought resilience index for each household.

$$
\begin{aligned}
D R I= & 0.2571 F_{c}-0.4216 M_{s}+0.1651 M_{c} \\
& +0.6156 A_{i}+0.5916 I_{p}
\end{aligned}
$$

The DRI was rescaled to ease interpretation and explanation of regression results and to allow ease of computation of treatment effects which can be interpreted as percentage increases-the rescaled index is bound between 0 and 1 (Giuseppe et al. 2016). A rescaling approach used by Keil et al. (2008) and Giuseppe et al. (2016) was adopted by the study since they have both worked with resilience to climate variability-induced shocks. An adopted min-max scaling was used to transform the DRI value into a standardized index, ranging between 0 and 1 (Giuseppe et al. 2016). The rescaling formula was stated in Eq. (7) as:

$$
X_{i}^{*}=\left(x_{\mathrm{i}}-x_{\min }\right) /\left(x_{\max }-x_{\min }\right)
$$

where $X_{i}^{*}$ and $x_{i}$ denote the individual households' transformed and untransformed DRIs, respectively; $x_{\max }$ and $x_{\min }$ represent the untransformed maximum and minimum DRIs, respectively, observed in the data set. From the results, the max and min values of untransformed DRI were 2.059 and -4.748 , respectively.

The transformation was then worked using Eq. (8) stated below:

$$
X_{i}^{*}=\left(x_{i}--4.748\right) /(2.059--4.748)
$$

Table 5 presents the summary statistics from the obtained standardized and unstandardized DRIs for all categories of households. After performing the independent samples $t$ test, the study fails to reject the

\begin{tabular}{|c|c|c|c|c|c|c|}
\hline \multirow[t]{2}{*}{ Variable } & \multicolumn{2}{|c|}{ Camel households } & \multicolumn{2}{|c|}{ Non-camel households } & \multirow{2}{*}{$\begin{array}{l}\text { Hypothesized } \\
\text { sign }\end{array}$} & \multirow{2}{*}{$\begin{array}{l}\text { Component } \\
\text { loading }\end{array}$} \\
\hline & Mean & Std. Dev. & Mean & Std. Dev. & & \\
\hline Number of alternative sources of income & 0.920 & 0.788 & 1.060 & 0.774 & + & 0.616 \\
\hline Proportion of off-farm income to total income & 0.260 & 0.353 & 0.440 & 0.381 & + & 0.592 \\
\hline Meals consumed per day in times of scarcity & 1.470 & 0.504 & 1.430 & 0.450 & + & 0.257 \\
\hline Proportion of food consumed in scarcity & 0.660 & 0.726 & 0.540 & 0.471 & + & 0.165 \\
\hline Months of scarcity & 5.000 & 4.847 & 5.890 & 4.622 & - & 0.422 \\
\hline
\end{tabular}
null hypothesis that camel-rearing households and non-camel-rearing households exhibit similar levels of

Table 4 Summary of variables used to construct a 'Drought Resilience Index' (DRI) 
Table 5 Summary statistics for the unstandardized and standardized DRIs obtained from principal component analysis

\begin{tabular}{lllll}
\hline DRI & All camel households, mean & Camel households, mean & Non-camel households, mean & $t$-statistic \\
\hline Unstandardized DRI & $-1.152(2.117)$ & $-1.101(2.160)$ & $-1.190(2.100)$ & -0.215 \\
Standardized DRI & $0.528(0.311)$ & $0.536(0.317)$ & $0.523(0.309)$ & -0.215 \\
\hline
\end{tabular}

Standard deviation in parentheses

resilience to droughts. This analysis is strengthened in the regression analysis using independent variables to control for differences between camel adopting and non-adopting households.

The unstandardized DRI in Table 5 ranges from negative to positive values with a mean value of -1.152 . The findings of the study are in tandem with those of Alinovi et al. (2008) and Alinovi et al. (2010) who found that pastoral communities in ASALs exhibited low resilience indices. The magnitude of indices across communities is not comparable due to the differences in other community characteristics and environments, but inferences from the signs of the indices can be compared (Giuseppe et al. 2016). The negative values were interpreted by the authors as non-resilient and the positive values as resilient with reference to a given household. This study adopted the same characterization. The categorization is broken into households below and above the 0 mark in Table 6 . While the surveyed households were generally found to be not resilient to droughts (DRI of 1.152), either of the categories has more than half of the surveyed households below the 0 cut-off, indicating low drought resilience among households in general.

\section{Econometric results and discussion}

The effect of camel rearing on household resilience to droughts

The study used the Lewbel-IV approach to determine the effect of camel adoption on household resilience to droughts. Table 6 presents the Lewbel-IV and OLS estimates. Due to the potential endogeneity between household resilience to droughts and camel adoption, OLS estimates could be biassed. The discussions hereafter follows Lewbel-IV estimates. The results in Table 6 show that both farm-specific (intensity of camel adoption and location) and household-specific (main occupation of the household head, education, and membership to associations) factors affect household resilience to droughts. The proportion of camels in the herd presents a positive and significant effect on household resilience to droughts. This value is significant at $10 \%$ level of significance.

Household resilience to droughts increased with the increase in the proportion of camels in the herd. Precisely, increasing the proportion of camels by one unit increased household resilience to droughts by $0.204 \%$ at $10 \%$ significance level. Livestock diversity is a long-term

Table 6 OLS and Lewbel-IV estimates of the factors influencing household's resilience to droughts

\begin{tabular}{|c|c|c|c|c|}
\hline \multirow[t]{2}{*}{ Variable (standardized resilience) } & \multicolumn{2}{|l|}{ Lewbel-IV } & \multicolumn{2}{|c|}{ Ordinary least squares (OLS) } \\
\hline & Coef. & Std. error & Coef. & Std. error \\
\hline Constant & $0.499^{*}$ & 0.024 & $0.668^{*}$ & 0.123 \\
\hline Proportion of camels to total herd & $0.204^{* * *}$ & 0.117 & 0.083 & 0.109 \\
\hline Age of household head (years) & 0.001 & 0.002 & 0.002 & 0.002 \\
\hline Occupation of household head (1, pastoralist; 0 , otherwise) & $-0.103^{* *}$ & 0.045 & -0.092 & 0.059 \\
\hline Household size (continuous) & 0.009 & 0.006 & 0.004 & 0.006 \\
\hline Dependence ratio & -0.026 & 0.031 & -0.022 & 0.030 \\
\hline Marital status (dummy) & -0.049 & 0.049 & -0.046 & 0.073 \\
\hline A household member completed primary (dummy) & $-0.153^{*}$ & 0.054 & $-0.144^{* *}$ & 0.065 \\
\hline Household accessed credit (dummy) & 0.078 & 0.048 & 0.072 & 0.056 \\
\hline Household received remittances (dummy) & 0.017 & 0.048 & 0.021 & 0.062 \\
\hline Membership to association (dummy) & $0.164^{*}$ & 0.055 & $0.163^{* *}$ & 0.062 \\
\hline Asset ownership ( 1 = agricultural and non-agricultural assets; $0=$ only agricultural assets) & -0.016 & 0.044 & 0.003 & 0.048 \\
\hline Crop area cultivated (acres) & 0.003 & 0.007 & 0.004 & 0.006 \\
\hline Received animal related extension services (dummy) & 0.053 & 0.051 & 0.038 & 0.057 \\
\hline District (dummy $1=$ Moroto; $0=$ Amudat) & $-0.494^{*}$ & 0.045 & $-0.460^{*}$ & 0.064 \\
\hline$R^{2}$ & 0.522 & & 0.541 & \\
\hline
\end{tabular}

***10\%, **5\%, and ${ }^{*} 1 \%$ level of significance. Standard errors in parentheses 
adaptation to shocks such as droughts, especially where both small and large ruminants are involved. Rushton (2009) argues that small ruminants are important in the immediate years after a shock to allow recovery of the stock due to their rapid proliferation capacities. In the long term, small ruminants (less stable) can be sold to buy more stable camels and hence keep the stock stable. This strategy provides long-term viability of livestock production in an uncertain environment. The large ruminants such as camels fetch higher incomes in the bad times which can be used to solve the households' immediate problems. In addition, the higher income fetched could be used in adopting other capital-intensive resilience-enhancing technologies.

In Table 6, the results show that the estimates for other determinants of household resilience to droughts are generally consistent with previous studies (Alinovi et al. 2008; Banda 2015; Keil et al. 2008) except for household levels of education. The study reveals that group membership positively affects household resilience to droughts while household head being mainly pastoralist, education, and location have a statistically negative effect on household resilience to droughts. Social capital in the form of belonging to a social group is positively related to household resilience to droughts at a $1 \%$ level of significance. A household belonging to a social group was $0.164 \%$ more resilient to droughts as compared to a household not in a social group.

This is consistent with the findings of Keil et al. (2008) who found that households that belonged to social groups were more resilient to ENSO-related droughts. Socially connected households are able to benefit from an extensive social network during times of crisis, allowing such households to go through a crisis with minimal damage to their core functioning as a unit. In addition, access to social safety nets can be associated with reduced use of asset liquidation options while coping with a shock for a given household.

The coefficient on the location of the household is negative and significant (at $1 \%$ level of significance). This implies that households in Moroto were less resilient than those in Amudat. Precisely, households in Moroto were less resilient than their Amudat counterparts. Similarly, the coefficient on the main occupation of the household head was negative and significant at a 5\% significance level. This means that pastoral households were less resilient than agro-pastoral and other livelihood-based houses. While households in Moroto mainly derive their livelihoods from livestock and livestock products, households from Amudat District have a mix of livestock, crop production, beekeeping, and some petty cross-border trade with Kenya. This could imply that purely livestock-based livelihoods are less resilient to droughts than mixed livelihoods. This result is consistent with that of Alinovi et al. (2010) who found that predominantly pastoral households in the Turkana region were least resilient in the event of food security hampering shocks, followed by agro-pastoral households. This highlights the importance of livelihood diversification by households in order to enhance resilience to shocks through increased livelihood stability.

Education levels of the household members were negatively correlated with household resilience to droughts at a $1 \%$ level of significance. The implication is that households with at least a member who had completed primary education were $0.153 \%$ less resilient compared to those households with no primary school completion at all. This result contradicts the findings of Keil et al. (2008) and Banda (2015) who found a positive relationship between household resilience to droughts and education. However, it should be noted that the studies of Keil et al. and Banda had measured education as the years of education attained by the household head. This study looked at education at the entire household level, whether there is a member of the household who has completed at least primary school. It should also be noted that the illiteracy rate in the study area is generally still high (only 17\% of the households had a member who had completed primary school). This limits drawing strong conclusions about the effect of education on resilience to shocks. Education is expected to increase household's access to off-farm income-generating activities and improve decision-making capabilities in the households. However, in the scenarios where returns to education are low due to limited opportunities for the educated, education may have no or even negative effects where it is expected to produce positive effects. This is because the investment in education turns out to be a loss to the investing household if the educated do not have opportunities to "repay" what has been invested in them.

\section{Conclusions and recommendations}

The main objective of the study was to determine the effect of camel adoption on household resilience to droughts. The study captured the level of adoption as the ownership of camels by a household, and intensity of camel adoption as the proportion of TLUs of camels in a household to the total livestock TLUs. The effect of camel adoption on household resilience to droughts was estimated using Lewbel's estimator, an innovative econometric estimator that accounts for potential endogeneity of a regressor by generating instrumental variables internally. A household resilience index was constructed using principal component analysis methods, and comparisons were made between camel-producing and noncamel-producing households in the communities chosen. PCA shows that income-smoothing indicators (increased 
off-farm income and alternative sources of income) had the greatest contribution to resilience. Econometric results show that the increasing proportion of camels in a herd by one tropical livestock unit significantly increased household resilience by $20 \%$. Other important drivers of resilience in households included: social capital in the form of group membership which positively affects household resilience to droughts; household head being predominantly pastoralist; completion of primary education by any household member, and households residing in Moroto District which negatively affected household resilience to droughts.

In conclusion, the study highlights the important role of not just livestock species diversification as a means of enhancing resilience to shocks but also adoption of drought-resilient livestock species as well as the importance of income-smoothing opportunities in enhancing household resilience to droughts. The results also reveal the importance of community-based livelihood diversification in enhancing household resilience to droughts. Both on-farm income-augmenting factors (location and proportion of camels) and off-farm factors (group membership and education) influence household resilience to droughts in pastoral households. This highlights the key complementarity relationship between the off-farm and on-farm sectors in enhancing household resilience to droughts. The study recommends increased emphasis on income diversification both on the farm and off the farm across programmes that aim to build household resilience to droughts.

\section{Abbreviations \\ ASALs: Arid and semi-arid lands; DRI: Drought Resilience Index; ENSO: El Niño-Southern Oscillation; FAO: Food and Agriculture Organization of the United Nations; IPCC: Intercontinental Panel on Climate Change; IUCN: International Union for Conservation of Nature; IV: Instrumental variable; KMO: Kaiser-Meyer-Olkin; NEMA: National Environmental Management Authority; PCA: Principal component analysis; RCI: Resilience Capacity Index; TLUs: Tropical livestock units; UBoS: Uganda Bureau of Statistics; UNDP: United Nations Development Program; USAID: United States Agency for International Development; USD: United States Dollar; UShs: Uganda shillings; WFP: The UN World Food Program}

\section{Acknowledgements}

Our deepest appreciation and gratitude is extended to the Regional Universities Forum for Capacity Building in Agriculture (RUFORUM) for funding this research. We thank the people of Karamoja for willingly availing and recognizing the great work done by our research assistants in collecting the information.

\section{Authors' contributions}

RA recruited, trained, and supervised the research assistant, analysed and structured the manuscript. JHA, RI, and GMD provided technical guidance on the econometrics methods and analysis. AE and JN provided administrative support, technical guidance on research methodologies, and general structuring of the manuscript. DKA provided guidance in the field during the data collection. All authors read, corrected, and approved the final manuscript.

\section{Funding}

The Regional Universities Forum for Capacity Building in Agriculture (RUFORUM) funded the study. RUFORUM as a funding body had no role in the design of the study and collection, analysis and interpretation of the data, and writing the manuscript.

\section{Availability of data and materials}

The data set generated and analysed during the current study is available from the corresponding author on reasonable request.

\section{Ethics approval and consent to participate}

The survey questionnaire solicited for consent as the first questions. Our research assistants were guided not to interview anyone who was not comfortable providing information.

\section{Consent for publication}

Not applicable

\section{Competing interests}

The authors declare that they have no competing interests.

\section{Author details}

${ }^{1}$ School of Agricultural Sciences, Makerere University, Kampala, Uganda. ${ }^{2}$ School of Forestry, Environmental and Geographical Science, Makerere University, Kampala, Uganda. ${ }^{3}$ Regional Universities Forum for Capacity Building in Agriculture (RUFORUM), Kampala, Uganda. ${ }^{4}$ National Livestock Resources Research Institute (NaLIRRI), Tororo, Uganda.

Received: 29 August 2019 Accepted: 30 January 2020

Published online: 27 March 2020

\section{References}

Ahmad, S., M. Yaqoob, N. Hashmi, S. Ahmad, M.A. Zaman, and M. Tariq. 2010 Economic importance of camel: Unique alternative under crisis. Pakistan Veterinary Journal 30 (4): 191-197 https://pdfs.semanticscholar.org/fbf1/6 e88d7c99b1b68b98829ad3adf23123ba44a.pdf.

Alinovi, L., M. d'Errico, E. Mane, and D. Romano. 2010. Livelihoods strategies and household resilience to food insecurity: An empirical analysis to Kenya. Italy: DiPSA, University of Florence https://www.researchgate.net/publication/2426 93358_Livelihoods_Strategies_and_Household_Resilience_to_Food_ Insecurity_An_Empirical_Analysis to Kenya. Accessed 27 Dec 2019.

Alinovi, L., E. Mane, and D. Romano. 2008. Measuring household resilience to food insecurity. Application to Palestinian households (Working paper). Food and Agriculture Organisation of the United Nations (FAO) https://www. researchgate.net/publication/228609523_Towards_the_Measurement_of_ Household_Resilience_to_Food_Insecurity_An_Application_to_Palestinian_ Households. Accessed 16 Jan 2019.

Aujla, K.M., M. Rafiq, and A. Hussain. 2013. The marketing system of live-camels and camel products in the desert ecologies of Pakistan. Pakistan Journal of Agricultural Research 26 (2): 130-142 https://www.soas.ac.uk/ camelconference2013/file89774.pdf.

Baltas, G., and P. Doyle. 2001. Random utility models in marketing research: A survey. Journal of Business Research 51 (2001): 115-125.

Banda, T.F. 2015. Determinants of household resilience to dry spells and drought in Malawi: A case of Chipoka. (Masters of Science in Agriculture and Applied Economics). University of Malawi https://ageconsearch.umn.edu/record/24346 9/. Accessed 28 June 2019.

Brookshire, E.N.J., and T. Weaver. 2015. Long-term decline in grassland productivity driven by increasing dryness. Nature Communications 6: 1-7.

Browne, S., \& Glaeser, L. 2010. Karamoja region food security assessment: Uganda Famine Early Warning Systems Network (FEWS NET), Kampala, Uganda. https://fews.net/sites/default/files/documents/reports/Karamoja\%20Food\%2 OSecurity\%20Assessment\%20January\%202010.pdf. Accessed 28 Nov 2019.

Caffrey, P., T. Finan, S. Trzaska, D. Miller, R. Laker-Ojok, and S. Huston. 2013. Uganda climate change vulnerability assessment report. Washington DC: USAID https://www.climatelinks.org/sites/default/files/asset/document/ARCCUganda\%2520VA-Report.pdf. Accessed 26 Jan 2020.

Ciani, F., and D. Romano. 2013. Testing for Household Resilience to Food Insecurity: Evidence from Nicaragua. Italy: University of Florence https://umw.siecon.org/sites/siecon.org/ files/oldfiles/uploads/2013/09/Ciani-Romano.pdf. Accessed on 20 Mar 2020.

Egeru, A., O. Wasonga, J. Kyagulanyi, G.M. Majaliwa, L. MacOpiyo, and J. Mburu. 2014. Spatio-temporal dynamics of forage and land cover changes in Karamoja subregion, Uganda. Pastoralism 4: 6 https://doi.org/10.1186/2041-7136-4-6. 
Elhadi, Y.A., M.D. Nyariki, and V.O. Wasonga. 2015. Role of camel milk in pastoral livelihoods in Kenya: contribution to household diet and income. Pastoralism, Research, Policy and Practice 5 (1) https://doi.org/10.1186/s13570-015-0028-7.

FAO, (Food and Agriculture Organisation of the United Nations). 2018. Resilience analysis in Karamoja, Uganda. Rome: FAO resilience analysis report, 10. Food and Agriculture Organization of the United Nations http://www.fao.org/3/ i8365en/l8365EN.pdf. Accessed 28 Jan 2020.

Farm-Africa. 2002. Micro-enterprise development. Best practices from FARM-Africa Nairobi. http://www.fao.org/tempref/docrep/nonfao/LEAD/X6174e/×6174e00. pdf. Accessed 20 Dec 2020.

Faye, B., O. Abdelhadi, A.I. Ahmed, and S.A. Bakheit. 2011. Camel in Sudan: Future prospects. Livestock Research for Rural Development 23 (10): 11.

Field, C.R., and J. Karuiki. 2005. Where there is no development agency: A manual for pastoralists and their promoters: (with special reference to the arid regions of the Greater Horn of Africa). Aylesford: NR International https://www.worldcat org/title/where-there-is-no-development-agency-a-manual-for-pastoralistsand-their-promoters-with-special-reference-to-the-arid-regions-of-the-greaterhorn-of-africa/oclc/64230785. Accessed 20 Jan 2019.

Giuseppe, S.D., R. Pietrelli, F. Grazio, M. d'Erico, and L. Russo. 2016. Resilience index measurement and analysis - II. Rome: Food and Agriculture Organisation of the United Nations http://www.fao.org/3/a-i5665e.pdf. Accessed 20 Nov 2019.

Guyu, F., and W. Muluneh. 2018. Food insecurity in the green famine belt of Ethiopia: Extent and severity in Belo-jiganfoy District, Benishangul-gumuz region. African Journal of Food Science 12 (3): 54-62.

Hanemann, W.M. 1984. Discrete/continuous models of consumer demand. Econometrica 52 (3): 541-551.

IPCC (Intercontinental Panel on Climate Change). 2014. Summary for policymakers. In Climate change 2014: Impacts, adaptation, and vulnerability. Part A: Global and sectoral aspects https://www.ipcc.ch/site/assets/uploads/2 018/02/ar5_wgll_spm_en.pdf. Accessed 26 Jan 2020.

IUCN (The International Union for Conservation of Nature). 2010. Building climate change resilience for African livestock in sub-Saharan Africa- World Initiative for Sustainable Pastoralism (WISP): A program of IUCN. https://www.iucn.org/ sites/dev/files/content/documents/resilence2.pdf. Accessed 26 Jan 2020.

Kagunyu, A., and J. Wanjohi. 2014. Camel rearing replacing cattle production among the Borana community in Isiolo County of Northern Kenya, as climate variability bites. Pastoralism, Research, Policy and Practice 4 (13): 1-5 https:// doi.org/10.1186/s13570-014-0013-6.

Kagunyu, A., and J. Wanjohi. 2015. The emergency of Euphorbia tiruculli as drought feeds for camels in northern Kenya. Pastoralism Research, Policy and Practice 5 (17): 4-16 https://doi.org/10.1186/s13570-015-0038-5.

Keil, A., M. Zeller, A. Wida, B. Sanim, and R. Birner. 2008. What determines farmers' resilience towards ENSO-related drought? An empirical assessment in Central Sulawesi, Indonesia. Climatic Change 86: 291-307 https://doi.org/10.1007/ s10584-007-9326-4.

Khan, B., A. Iqbal, and M. Riaz. 2003. Production and management of camels. Faisalabad: T. M. Printers.

Kima, S.A., A.A. Okhimamhe, A. Kiema, N. Zampaligre, and I. Sule. 2015. Adapting to the impacts of climate change in the sub-humid zone of Burkina Faso, West Africa: Perceptions of agropastoralists. Pastoralism, Research, Policy and Practice 5 (16) https://doi.org/10.1186/s13570-015-0034-9.

Lewbel, A. 2012. Using heteroscedasticity to identify and estimate mismeasured and endogenous regressor models. Journal of Business \& Economic Statistics 30 (1): 67-80

Lickley, M., and S. Solomon. 2018. Drivers, timing and some impacts of global aridity change. Environmental Research Letters 13 (2018): 104010 https://doi. org/10.1088/1748-9326/aae013.

Mishra, V., and R. Smyth. 2015. Estimating returns to schooling in urban China using conventional and heteroskedasticity-based instruments. Economic Modelling 47: 166-173.

Mochabo, K.O.M., P.M. Kitala, P.B. Gathura, W.O. Ogara, A. Catley, E.M. Eregae, and T.D. Kaitho. 2005. Community perceptions of important camel diseases in Lapur division of Turkana District, Kenya. Tropical Animal Health and Production 37 (2005): 187-204.

Mubiru, D.N. 2010. Climate change and adaptation options in Karamoja. A report submitted to Food and Agriculture Organization and European Union, 62. Kampala: https://pdfs.semanticscholar.org/eae4/e9dab59ab65ebf737bccd15 dbb1aba64bf33.pdf. Accessed 25 Jan 2020.

Muricho, D.N., D.J. Otieno, W. Oluoch-Kosura, and M. Jirström. 2019. Building pastoralists' resilience to shocks for sustainable disaster risk mitigation:
Lessons from West Pokot County, Kenya. International Journal of Disaster Risk Reduction 34: 429-435.

Musinga, M., D. Kimenye, and P. Kivolonzi. 2008. The camel milk industry in Kenya Results of a study commissioned by SNV to explore the potential of Camel Milk from Isiolo District to access sustainable formal markets. Kenya: Netherlands Development Organisation (SNV) https://www.afraca.org/download/general_ rf_publications/Camel-Milk-Value-Chain-The-Case-of-Isiolo-District-A-StudyReport-by-Muli-Musinga-et-al.pdf. Accessed on 10 Mar 2020.

Nardo, M., M. Saisana, A. Saltelli, S. Tarantola, A. Hoffmann, and E. Giovannini. 2008. Handbook on constructing composite indicators: Methodological and user guide. https://doi.org/10.1787/533411815016 ISBN: 978-92-64-04345-9, OECD.

Opiyo, F., O. Wasonga, and M. Nyangito. 2014. Measuring household vulnerability to climate-induced stresses in pastoral rangelands of Kenya: Implications for resilience programming. Pastoralism, Research, Policy and Practice 4 (10) http://www.pastoralismjournal.com/content/4/1/10.

Opiyo, F., O. Wasonga, M. Nyangito, J. Schilling, and R. Munang. 2015. Drought adaptation and coping strategies among the Turkana pastoralists of Northern Kenya. International Journal of Disaster Risk Science 6 (3): 295-309 https://doi. org/10.1007/s13753-015-0063-4. Accessed 27 Jan 2020.

Osbahr, H., C. Twyman, W.N. Adger, and D.S.G. Thomas. 2010. Evaluating successful livelihood adaptation to climate variability and change in southern Africa. Ecology and Society 15 (2): 27 http://www.ecologyandsociety.org/ vol15/iss2/art27/.

Oxfam. 2008. Survival of the fittest pastoralism and climate change in East Africa. Oxfam briefing paper. https://oxfamilibrary.openrepository.com/bitstream/ handle/10546/114607/bp116-survival-fittest-east-africa-180808-en. pdf? sequence=1\&isAllowed=y. Accessed 27 Jan 2020.

Rushton, J. 2009. The economics of animal health and production. United Kingdom: MPG Books Ltd, Bodmin https://books.google.co.ug/books?hl= en\& $\mid r=\& i d=i C y A B k j k R J 0 C \& o i=f n d \& p g=P R 5 \& d q=$ Rushton, $+J .+(2009) .+$ The+ Economics+of+Animal+Health+and+Production.+United+Kingdom:+MPG+ Books+Ltd,+Bodmin.\&ots=kUatGKZRct\&sig=pBqBDd4l-oNUGyKuOk5d2 iWZfF0\&redir_esc=y\#v=onepage\&q\&f=false. Accessed 14 May 2019.

UBoS (Uganda Bureau of Statistics). 2010. The national livestock census report 2008. Kampala: https://www.ubos.org/wp-content/uploads/publications/05_2019THE_ NATIONAL_LIVESTOCK_CENSUS_REPORT_2008.pdf. Accessed 26 Jan 2020.

United Nations Development Program (UNDP). 2009. Climate change in the African drylands: Options and opportunities for adaptation and mitigation. Nairobi: https://www.droughtmanagement.info/literature/UNCCD_climate_ change_african_drylands_2009.pdf. Accessed 3 Jan 2020.

USAID. 2005. Conflict baseline study report conducted in the Karamajong cluster of Kenya and Uganda [online]. Washington, D.C: https://karamojaresilience.org/ publications/item/conflict-early-warning-and-mitigation-of-resource-basedconflicts-in-the-greater-horn-of-africa-conflict-baseline-study-report-conductedin-the-karamajong-cluster-of-kenya-and-uganda. Accessed 15 Jan 2020.

Ventura, M. 2018. Testing the validity of instruments in an exactly identified equation. International Journal of Computational Economics and Econometrics 8 (2) https://doi.org/10.1504/IJCEE.2018.091038. Accessed 19 Dec 2019.

Vetter, S. 2009. Drought, change and resilience in South Africa's arid and semiarid rangelands. South African Journal of Science 105: 29-33.

World Food Program of the United Nations (WFP). 2009. Country Strategy for WFP in Uganda (2009-2014). https://docs.wfp.org/api/documents/WFP0000025764/download/. Accessed 22 Oct 2019.

Yosef, T., K. Kefelegn, Y.K. Mohammed, U. Mengistu, A. Solomon, D. Tadelle, and J. Han. 2014. Morphological diversities and eco-geographical structuring of Ethiopian camel (Camelus dromedarius) populations. Journal of Food Agriculture and Environment 26 (4): 371-389 https://doi.org/10.9755/ejfa.v26i4.17021.

Zwaagstra, L., Sharif, Z., Wambile, A., Leeuw, J. d., Johnson, N., Njuki, J., Herrero, M. 2010. An assessment of the response to the 2008-2009 drought in Kenya: A report to the European Union Delegation to the Republic of Kenya. https:// cgspace.cgiar.org/bitstream/handle/10568/2057/assessment_drought_2010. pdf?sequence=3. Accessed 3 June 2019.

\section{Publisher's Note}

Springer Nature remains neutral with regard to jurisdictional claims in published maps and institutional affiliations. 